\title{
1 Title: Rate of photosynthetic acclimation to fluctuating light varies widely \\ 2 among genotypes of wheat
}

3

4 Running title: Variation in photosynthetic acclimation kinetics in wheat

$6 \quad$ William T. Salter ${ }^{1}$ (william.salter@sydney.edu.au)

7 Andrew M. Merchant ${ }^{1}$ (andrew.merchant@sydney.edu.au)

8 Richard A. Richards ${ }^{2}$ (richard.richards@csiro.au)

9 Richard Trethowan ${ }^{1}$ (richard.trethowan@sydney.edu.au)

10 Thomas N. Buckley ${ }^{3, *}$ (tnbuckley@ucdavis.edu)

${ }^{1}$ School of Life and Environmental Sciences, Sydney Institute of Agriculture, The University

13 of Sydney, Brownlow Hill, NSW 2570, Australia

$14{ }^{2}$ CSIRO, Agriculture and Food, GPO Box 1700, Canberra, ACT, 2601, Australia

${ }^{3}$ Department of Plant Sciences, University of California, Davis, Davis, CA 95616, USA

${ }^{*}$ Corresponding author: +19169179217

19 Submission date: $5^{\text {th }}$ October 2018

20 Number of tables: 0

21 Number of figures: 7 ( 2 black and white, 5 in colour for print and online)

22 Word count: 5214 


\section{$24 \quad$ Highlight}

25 Significant variation exists in the acclimation time of photosynthesis following dark-to-light

26 transitions across wheat genotypes, under field and controlled conditions. Slow acclimation

27 reduced daily carbon assimilation by up to $16 \%$.

\section{Abstract}

30 Crop photosynthesis and yield are limited by slow photosynthetic induction in sunflecks. We

31 quantified variation in induction kinetics across diverse genotypes of wheat for the first

32 time. In a preliminary study using penultimate leaves of 58 genotypes grown in the field, we

33 measured induction kinetics for maximum assimilation rate $\left(A_{\max }\right)$ after a shift from full

34 darkness to saturating light $\left(1700 \mu \mathrm{mol} \mathrm{m}^{-2} \mathrm{~s}^{-1}\right)$ with 1-4 replicates per genotype. We then

35 grew 10 of these genotypes with contrasting responses in a controlled environment and

36 quantified induction kinetics of carboxylation capacity $\left(V_{c m a x}\right)$ from dynamic $A$ vs $c_{i}$ curves

37 after a shift from low to high light (50 to $1500 \mu \mathrm{mol} \mathrm{m} \mathrm{m}^{-1}$ ), with 5 replicates per genotype.

38 Within-genotype median time for $95 \%$ induction $\left(t_{95}\right)$ varied from 8.4 to $23.7 \mathrm{~min}$ across

39 genotypes for $A_{\max }$ in field-grown penultimate leaves, and from 6.7 to $10.4 \mathrm{~min}$ for $V_{\text {cmax }}$ in

40 chamber-grown flag leaves. Our simulations suggested that non-instantaneous acclimation

41 reduces daily net carbon gain by up to $16 \%$, and that breeding to speed up $V_{\text {cmax }}$ induction in

42 the slowest genotype to match that in the fastest genotype could increase daily net carbon

43 gain by more than $4 \%$, particularly for leaves that experience predominantly short-duration

44 sunflecks.

46 Keywords: photosynthesis, wheat, rubisco activase, sunfleck, phenotyping, modelling. 


\section{Introduction}

50 Global food security is threatened by growing populations and diminishing increases in crop

51 yield potential. To ensure future food security, improvements need to be made to plant

52 yield traits that have previously been overlooked in crop breeding programs, such as

53 dynamic properties of photosynthesis. The efficiency of photosynthetic machinery under

54 fluctuating environmental conditions has been identified as a key target for improvement

55 (Taylor \& Long, 2017; Murchie et al., 2018). In particular, the light environment of crop

56 canopies is highly dynamic, with fluctuations occurring on the scale of seconds to minutes

57 (Slattery et al., 2018). On clear days, leaves at the top of the canopy are generally exposed

58 to direct sunlight for the majority of the day, whilst leaves in the lower canopy rely on light

59 in the form of sunflecks. These sunflecks can account for up to $90 \%$ of the daily available

60 light (Pearcy, 1990).

62 The impact of rapid shifts in photosynthetic photon flux density (PPFD) on carbon balance is

63 influenced by a number of physiological factors. Diffusion of $\mathrm{CO}_{2}$ through stomata and the

64 mesophyll (controlled by conductances $g_{\mathrm{s}}$ and $g_{\mathrm{m}}$ respectively) can limit induction of

65 photosynthesis (Lawson \& Vialet-Chabrand, 2018), and conversely, slow deactivation of energy-consuming photoprotective mechanisms when leaves enter shadeflecks can reduce net carbon gain (Kromdijk et al., 2016). Slow acclimation of photosynthesis following shade to sun transitions can also substantially reduce carbon assimilation in crop canopies. Activation of ribulose-1,5-bisphosphate carboxylase/oxygenase (Rubisco) is considered to be a critical constraint on photosynthetic induction to shade-sun transitions (Soleh et al., 2016; Taylor \& Long, 2017; Morales et al., 2018). In a recent study, Taylor \& Long (2017) predicted that carbon assimilation could be inhibited by up to $21 \%$ in wheat (Triticum aestivum) by slow induction of Rubisco in response to fluctuating light conditions. If this inefficiency could be reduced, whole canopy carbon assimilation would be improved, potentially leading to increases in yield (Long et al. 2006).

Screening for genetic variation in photosynthetic activation time would increase our fundamental understanding of this process and patterns in variation and dynamics of the response would allow us to identify whether this trait is a valid target for improvement through conventional breeding. However, although some variation in the kinetics of 
81 photosynthetic acclimation has been identified across soybean genotypes (Soleh et al.,

82 2016; Soleh et al. 2017), there is little information available regarding the diversity of this

83 trait in wheat. Taylor and Long (2017) examined only a single genotype, partly due to the

84 arduous nature of the "dynamic $A$ vs $c_{i}$ " method they used to characterize the kinetics of

85 Rubisco activation in vivo. Other less direct methods such as in vitro Rubisco assays, or high-

86 throughput phenotyping (HTP) field techniques such as multispectral imaging, could be

87 applied more readily to the task of phenotyping many genotypes. However, in vitro assays

88 do not capture the interaction of diffusional and biochemical induction. Stomatal and

89 mesophyll diffusion influence $\left[\mathrm{CO}_{2}\right]$ in chloroplasts, which in turn regulates Rubisco activase

90 (Portis et al., 1986) - and HTP methods cannot yet quantify photosynthetic rate per se, nor

91 its induction kinetics. Direct measurement of gas exchange in intact leaves thus remains, in

92 our view, the only suitable method for phenotyping these traits.

94 We used a three-phase approach to quantify the extent of genetic variation in

95 photosynthetic acclimation kinetics in wheat and the potential for directed breeding to

96 enhance productivity by harnessing this variation. First, we measured the kinetics of

97 acclimation for $\mathrm{CO}_{2}$-saturated photosynthesis after a shift from darkness to saturating light

98 in penultimate leaves of 58 genotypes of field-grown wheat. Second, we then studied

99 acclimation kinetics more intensively for a subset of 10 of these genotypes, using the

100 dynamic $A$ vs $C_{i}$ method to quantify induction of RuBP carboxylation and regeneration

101 capacities over time after a switch from low to high light. Finally, we used modeling to

102 quantify the improvement in diurnal net carbon gain that could be achieved by breeding for

103 faster photosynthetic induction within the observed range of variation across genotypes.

104

105 


\section{Methods}

107 Plant material

108 Detailed analysis of photosynthetic acclimation was conducted on wheat grown under controlled conditions in June/July 2018. 10 genotypes were selected from those grown in the field the previous year (Table S1). Seed was sown in 5 I pots with compost mix containing a slow release fertiliser (Evergreen Garden Care Australia, Bella Vista, NSW, Australia). Day and night temperatures were maintained at $23.7 \pm 1.7^{\circ} \mathrm{C}$ and $12.0 \pm 1.8^{\circ} \mathrm{C}$ (mean \pm s.d.) respectively, and relative humidity at $67.2 \pm 6.1 \%$ and $74.0 \pm 8.1 \%$. Growth $\mathrm{CO}_{2}$ concentration was $482.2 \pm 23.2 \mu \mathrm{mol} \mathrm{mol}^{-1}$ across the course of the experiment. Light was supplied by LED growth lamps (LX602C; Heliospectra AB, Göteborg, Sweden) and provided a PPFD of $800 \mu \mathrm{mol} \mathrm{m}^{-2} \mathrm{~s}^{-1}$ at the leaf surface. Seedlings were thinned to one per pot after germination. Plants were watered twice daily to field capacity. All gas exchange measurements were taken on the mid-section of a fully expanded flag leaf during heading or anthesis (the distribution of Zadoks phenological growth stages during these

For measurement of photosynthetic acclimation in field-grown plants, wheat was planted in $2 \times 6 \mathrm{~m}$ plots with 5 sowing rows per plot in Narrabri, NSW, Australia in late May 2017. 58 genotypes were examined here (Table S1). Measurements were made on 03-18 Sep 2017, within two weeks before or after anthesis (the distribution of Zadoks phenological stages across the field measurement campaign is shown in Figure S1).

Detailed analysis of acclimation to light in flag leaves of wheat grown in a controlled environment

Plants were moved from the controlled environment room to a temperature stable laboratory at $25^{\circ} \mathrm{C}$. Photosynthetic light response curves were recorded using a LI-6400 gas exchange system (Li-Cor, Lincoln, NE, USA) on one plant of each genotype. Leaves were equilibrated to chamber conditions (leaf temperature $25^{\circ} \mathrm{C}$; leaf vapour pressure deficit 1.0$1.5 \mathrm{kPa}$; cuvette $\mathrm{CO}_{2}\left(C_{\mathrm{a}}\right) 400 \mu \mathrm{mol} \mathrm{mol}{ }^{-1}$; and PPFD $1500 \mu \mathrm{mol} \mathrm{m} \mathrm{s}^{-2}$ provided by LEDs in the chamber head) for at least 40 min to allow them to reach steady state. PPFD was then reduced through 1200, 1000, 800,600,500,400,300, 200, 150, 100, 50 and $0 \mu_{\mathrm{mol} \mathrm{m}}^{-2} \mathrm{~s}^{-1}$, with measurements taken immediately after chamber conditions had stabilized at each 
138

139

140

141

142

143

144

145

146

147

148

149

150

151

152

153

154

155

156

157

158

159

160

161

162

163

164

level. Light responses curves were fitted to a non-rectangular hyperbola model using nonlinear least squares in $\mathrm{R}$ ( $\mathrm{n} / \mathrm{s}$; R Language and Environment); i.e., the lesser $\operatorname{root} A$ of

$$
\theta\left(A-R_{d}\right)^{2}-\left(\phi i+A_{s a t}\right)\left(A-R_{d}\right)+\phi i A_{s a t}=0
$$

where $i$ is PPFD, $A_{\text {sat }}$ is the asymptotic limit of $A$ at high PPFD, $\theta$ is a dimensionless parameter $<1, \phi$ is the initial slope of $A_{\mathrm{eq}} \mathrm{vs} i$, and $R_{\mathrm{d}}$ is day respiration rate. $A_{\mathrm{sat}}, \theta, \phi$ and $R_{\mathrm{d}}$ were fitted empirically.

Dynamic $A$ vs $c_{\mathrm{i}}$ responses were recorded using four Walz GFS-3000 gas exchange systems (Heinz Walz GmbH, Effeltrich, Germany), using the method of Taylor \& Long (2017). The acclimation of photosynthesis following transition from shade to saturating light was measured at a number of different $c_{\mathrm{a}}$ values, and composite $A$ vs $c_{\mathrm{i}}$ curves were generated for each relative time point during induction. Leaf temperature was held at $25^{\circ} \mathrm{C}$ and $V P D_{\text {leaf }}$ at $1.0 \mathrm{kPa}$. Each leaf was first brought to a steady state at $c_{\mathrm{a}} 400 \mu \mathrm{mol} \mathrm{mol}^{-1}$ and PPFD 1500 $\mu \mathrm{mol} \mathrm{m} \mathrm{m}^{-1}$ (found to be saturating in our light response curves) over $40 \mathrm{~min}$, and PPFD in the leaf chamber was then dropped to $50 \mu \mathrm{mol} \mathrm{m}^{-2} \mathrm{~s}^{-1}$ for $30 \mathrm{~min}$. During this 'dark phase' the $c_{\mathrm{a}}$ was also reduced to $100 \mu \mathrm{mol} \mathrm{mol}{ }^{-1}$ to inhibit stomatal closure, as per guidelines in Taylor \& Long (2017). Prior to induction the $c_{a}$ was increased to the desired value for induction. Induction of photosynthesis was initiated with a step change to PPFD $1500 \mu \mathrm{mol}$ $\mathrm{m}^{-2} \mathrm{~s}^{-1}$, and measurements recorded every 10 seconds for $15 \mathrm{~min}$. This $30 \mathrm{~min}$ dark $-15 \mathrm{~min}$ light cycle was repeated at induction $c_{\mathrm{a}}$ of $50,100,200,300,400,500,600,800$ and 1000 $\mu \mathrm{mol} \mathrm{mol}{ }^{-1}$.

$A v s c_{\mathrm{i}}$ curves were generated for each $10 \mathrm{~s}$ time point after induction of photosynthesis. The Farquhar et al. (1980) photosynthesis model was fitted to these curves using the 'plantecophys' package in R (bilinear fitting method; Duursma, 2015) to provide estimates of Rubisco carboxylation capacity $\left(V_{\text {cmax }}\right)$ and electron transport rate $(J) . R_{\mathrm{d}}$ was set at $1.9 \mu \mathrm{mol}$ $\mathrm{m}^{-2} \mathrm{~s}^{-1}$ and $\theta$ was set at 0.67 (from our light response curves). We also provided the Michaelis-Menten coefficient and the photorespiratory compensation point, calculated from the mean leaf temperature as per Bernacchi et al. (2001). Temperature corrections 
169

170

171

172

173

174

175

176

177

178

179

180

181

182

183

184

185

186

187

188

189

190

191

192

193

194

195

196

197

were performed during the fitting process to provide values of $V_{\mathrm{cmax}}$ and $J$ at $25^{\circ} \mathrm{C}$. The script used for curve fitting is provided in Supporting Information File S2.

For each leaf, we modeled the observed timecourse of induction of $V_{\text {cmax }}$ using a two-phase exponential function of time:

$$
V_{\text {cmax }}(t)=V_{m i}+\left(V_{m f}-V_{m i}\right)\left\{f\left(1-\exp \left(-\frac{t}{\tau_{\text {fast }}}\right)\right)+(1-f)\left(1-\exp \left(-\frac{t}{\tau_{\text {slow }}}\right)\right)\right\}
$$

where the parameters ( $V_{\mathrm{mi}}$ and $V_{\mathrm{mf}}$ are the initial and final (fully acclimated) values of $V_{\mathrm{cmax}}$, $\tau_{\text {fast }}$ and $\tau_{\text {slow }}$ are time constants for fast and slow phases of acclimation, respectively, and $f$ is a weighting factor between zero and one) were estimated by using Solver in MS Excel to minimize the sum of squared differences between measured and modeled $V_{\text {cmax. }}$. We found that this two-phase model produced a substantially better fit to our data than a singlephase model as used by Taylor and Long (2017), with $r^{2}$ ranging from 0.957 to 0.996 (median $=0.990)$.

\section{Photosynthetic acclimation to light in penultimate leaves of field grown wheat}

We used OCTOflux to measure photosynthetic acclimation upon transition from darkness to saturating light in penultimate leaves of 58 genotypes of field grown wheat. This system is described elsewhere (Salter et al., 2018). It is an open-flow single-pass differential gas exchange system with eight leaf chambers $(5 \times 11 \mathrm{~cm})$, designed to maximize throughput for measurements of $\mathrm{CO}_{2}$ - and light-saturated net photosynthesis rate $\left(A_{\max }\right)$. Each chamber has a white LED light source above the adaxial leaf surface, a Propafilm window, four small mixing fans and a type $T$ thermocouple kept appressed to the abaxial surface. Stable dry air is created by mixing $\mathrm{CO}_{2}$ and dry air from pressurized cylinders with mass flow controllers into a buffering volume ( $40 \mathrm{~L}$ ) containing a powerful fan. This gas is then split into nine streams: a reference stream, which flows through the reference cell of a differential infrared gas analyzer (IRGA; Li-7000, Li-Cor, Lincoln, Nebraska), and eight sample streams, each of which runs through a mass flow meter to a leaf chamber and back to the IRGA, where it is 
198

199

200

201

202

203

either vented to the atmosphere or directed through the IRGA sample cell, using solenoid valves.

Tillers were cut in the field, immediately recut under distilled water and placed into darkness and transported by vehicle to the laboratory (about $1 \mathrm{~km}$ away; time from cutting to laboratory was 5-15 $\mathrm{min}$ ), and kept in darkness for a further $0-30$ minutes before measurement. Each leaf was enclosed in a leaf chamber and exposed to saturating PPFD $\left(1700 \mu \mathrm{mol} \mathrm{m} \mathrm{s}^{-1}\right)$ and ambient $\mathrm{CO}_{2}\left(4800-5000 \mu \mathrm{mol} \mathrm{mol}^{-1}\right)$, and then allowed to acclimate to these conditions. To verify that $A_{\max }$ measured at these high $c_{\mathrm{a}}$ values did not differ substantially from the true $A_{\max }$, which occurs at the transition point between RuBPregeneration-limited and triose phosphate utilization (TPU) limited photosynthesis, we measured traditional $A$ vs $c_{\mathrm{i}}$ curves in 18 leaves and extrapolated these to high $c_{\mathrm{a}}$ using a biochemical model (Farquhar et al. 1980) as extended by Busch et al. (2018), and found that $A_{\max }$ at $5000 \mu \mathrm{mol} \mathrm{mol}{ }^{-1}$ was an excellent proxy for true $A_{\max }\left(\mathrm{r}^{2}=0.9841\right.$, slope $=0.9968$;

Figure S2). Full details of these tests are given in Salter et al. (2018).

The present study took advantage of the fact that the sample gas stream from one of the eight chambers could be continuously measured during photosynthetic acclimation to saturating light. We recorded net $\mathrm{CO}_{2}$ assimilation rate every two seconds until stability was achieved (average $14 \mathrm{~min}$ ), and the record of $A$ vs time was then modeled with the following sigmoidal equation:

$$
A(t)=A_{\text {init }}+\left(A_{\max }-A_{\text {init }}\right) \exp (-a \cdot \exp (-b t))
$$

where $A_{\text {init, }}, A_{\text {max }}, a$ and $b$ are positive empirical parameters fitted by using Solver (GRG nonlinear engine) in Microsoft Excel to minimize the sum of squared differences between measured and modeled $A$. The times for $A$ to rise by $25 \%, 75 \%$ and $95 \%$ of the difference between $A_{\text {init }}$ and $A_{\max }\left(t_{25}, t_{75}\right.$ and $t_{95}$, respectively) were then calculated from the fitted parameters, as $t_{\mathrm{x}}=\ln (a / \ln (1 /[0.01 \cdot x])) / b$, where $x=25,75$ or 95 . The "rise time," or the time required for $A$ to increase through the middle $50 \%$ of its dynamic range, was calculated as $t_{75}-t_{25}$ 
230 Because the workflow was organized around the broader phenotyping study (in which 160

231 genotypes were measured), replication was unbalanced among the 58 genotypes for which we recorded acclimation kinetics, with $n=1$ to 4 replicate plants per genotype.

\section{Modeling impact of acclimation kinetics on carbon gain}

235 We simulated the impact of observed variability in photosynthetic acclimation kinetics on

236 diurnal carbon gain for different sunfleck lengths and canopy positions, using a modeling

237 approach similar to that of Taylor and Long (2017), and simulating $V_{c m a x}$ induction kinetics

238 using median kinetic parameters for the slowest and fastest of the 10 genotypes studied. To

239 assess the role of sunfleck length and canopy position, we calculated irradiance based on

240 expressions given by Retkute et al. (2018) and de Pury and Farquhar (de Pury \& Farquhar,

241 1997), rather than the sample ray tracing model output used by Taylor and Long (2017). The

242 modeling approach is described in detail in Appendix S1; sample diurnal traces of leaf

243 irradiance, including alternating sunflecks and shadeflecks, are shown in Figure 1.

Analysis of $A$ vs $c_{\mathrm{i}}$ data with the 'one-point method'

We tested whether the 'one-point method' of De Kauwe et al. (2016) would provide robust estimates of $V_{\text {cmax }}$ during photosynthetic acclimation to dark-to-light transitions. For this analysis we used the dark-to-light photosynthetic induction at $c_{\mathrm{a}} 400 \mu \mathrm{mol} \mathrm{mol}^{-1}$ from our dynamic $A$ vs $C_{i}$ analysis, and estimated $V_{\text {cmax }}$ by fitting the Farquhar et al. (1980) model to the data using the 'plantecophys' package in R (Duursma, 2015).

\section{Statistical analysis}

We tested for differences among genotypes in functional parameters of acclimation kinetics ( $t_{95}$ and $t_{75}-t_{25}$ ) using analysis of variance (function aov() in base $\mathrm{R}$ ) with genotype as a categorical independent variable and $t_{95}$, etc., as dependent variables (after transformation to improve normality, by inversion [i.e., $y=1 / t_{95}$ ] for chamber-grown plants, and by log transformation for field-grown plants). Outliers for $t_{95}$ and $t_{75}-t_{25}$ were removed from the $V_{c \operatorname{cmax}}$ dataset on the basis of a Grubbs test (R package 'outliers') applied to each genotype; 


\section{Results}

Measurement and modeling of acclimation kinetics

$264 A$ vs $c_{i}$ curves fit to each $10 \mathrm{~s}$ interval following transition from shade $\left(50 \mu \mathrm{mol} \mathrm{m}^{-2} \mathrm{~s}^{-1}\right)$ to saturating light $\left(1500 \mu \mathrm{mol} \mathrm{m} \mathrm{s}^{-1}\right)$ revealed limitations imposed by $V_{\mathrm{cmax}}$ at lower $c_{\mathrm{i}}$ and by $J$ at higher $c_{i}$ throughout induction. Whilst specific acclimation times varied between individual leaves and among genotypes (fitted dynamic $A$ vs $c_{i}$ curves for a slow and a fast acclimating leaf are shown in Fig $2 \mathrm{a}$ and $2 \mathrm{~b}$ respectively), general trends in induction kinetics were clear (Fig S3). Both $V_{\text {cmax }}$ and $J$ increased immediately after transition to saturating light, however $J$ increased more rapidly than $V_{\mathrm{cmax}}$ in the first three minutes and also saturated more quickly. As a result, $c_{i}$, rans $\left(\right.$ the $c_{\mathrm{i}}$ at which the primary limitation imposed on photosynthesis switches between $V_{c \max }$ and $J$ ) rose to a maximum of $563 \pm 3.2 \mathrm{\mu mol} \mathrm{mol}^{-1}$ three minutes after transition to saturating light, decreasing to $422 \pm 4.1 \mu^{m o l ~ m o l}{ }^{-1}$ after seven minutes and remaining relatively stable after this time (Fig S3c). The high values of $c_{i, \text { trans }}$ throughout induction indicate that $V_{c m a x}$ is likely always limiting to photosynthesis under field conditions (assuming $c_{\mathrm{a}}$ of approx. $400 \mu \mathrm{mol} \mathrm{mol}^{-1}$ ). A two-phase exponential model was fitted to the measured $V_{\text {cmax }}$ data with $r^{2}$ ranging from 0.957 to 0.996 (median $=$ $0.990)$, a representative timecourse of $V_{c \max }$ induction is shown in Figure $3 \mathrm{~b}$.

Photosynthetic induction kinetics of plants grown under field conditions differed from those to saturating light. A representative timecourse of $A_{\max }$ induction of field grown plants is shown in Figure 3a. A sigmoidal equation was fitted to the acclimation kinetics of $A_{\max }$ of field grown plants with median $r^{2}>0.99$.

\section{Variation in photosynthetic induction kinetics}

For $A_{\max }$ in penultimate leaves of field-grown wheat, within-genotype median $t_{95}$ (the time for $A_{\max }$ to rise through $95 \%$ of its dynamic range) ranged from 8.4 to $23.7 \mathrm{~min}$ across genotypes (Fig 4a). The within-genotype median for $t_{75}-t_{25}$ (the time required for $A_{\max }$ to increase through the middle $50 \%$ of its dynamic range) varied from 1.5 to $7.6 \mathrm{~min}$ (Fig 4b). 
2920.81 for $t_{95}$, and $F(57,73)=0.94, p=0.6$ for $\left.t_{75}-t_{25}\right)$. Across genotypes the final $A_{\max }$ was

293 unrelated to $t_{95}\left(r^{2}=0.027, p=0.058\right)$ or $t_{75}-t_{25}\left(r^{2}<0.001, p=0.923\right)$ (Fig S4a and S4c).

294

295 The rate of induction also varied greatly across genotypes for $V_{\text {cmax }}$ in flag leaves of chamber-

296 grown wheat. Within-genotype medians ranged from 6.7 to 10.4 for $t_{95}$, and from 2.2 to 3.1

297 for $t_{75}-t_{25}$ (Fig 4c,d). Differences among genotypes were highly significant for $t_{95}(F(9,37)=$

$2983.97, p=0.0013)$, but not significant for $t_{75}-t_{25}(F(9,37)=1.99, p=0.07)$. The corresponding

299 within-genotype median time constants for the fast and slow phases of acclimation, $\tau_{\text {fast }}$ and

$300 \tau_{\text {slow, }}$, respectively, ranged from $0.05 \mathrm{~min}$ to $0.51 \mathrm{~min}\left(\tau_{\text {fast }}\right)$ and from 2.6 to $4.5 \mathrm{~min}\left(\tau_{\text {slow }}\right)$;

301 the weighting factor for the fast phase $(f)$ was 0.39 in the fastest genotype and 0.49 in the

302 slowest. Figure 5 shows representative time-courses of acclimation of normalized $V_{c \max }$

303 corresponding to these lower and upper deciles for $\tau_{\text {fast }}$ and $\tau_{\text {slow }}$. The final $V_{\text {cmax }}$ was

304 unrelated to $t_{95}\left(r^{2}=0.072, p=0.060\right)$ but was loosely correlated with $t_{75}-t_{25}\left(r^{2}=0.146, p=\right.$

305 0.006) (Fig S4b and S4d).

306

\section{Simulated effect of variation in acclimation kinetics on diurnal carbon gain}

308 Our simulations predicted that non-instantaneous acclimation of photosynthesis to

309 sunflecks could reduce daily carbon gain by as much as $16 \%$ (Figure 6a). The reduction was

310 generally greatest for shorter-duration sunflecks, because photosynthesis has less

311 opportunity to approach its fully acclimated "target" value during short sunflecks. This

312 reduction was greater for the slowest genotype than for the fastest under most conditions,

313 with the exception of short-duration sunflecks in upper-canopy leaves ( $L A=0.25 \mathrm{~m}^{2} \mathrm{~m}^{-2}$ )

314 (Figure 6a). Leaf orientation had fairly small effects on simulated carbon losses due to slow

315 induction (Figure S5), so results presented in the main text were integrated over a spherical

316 leaf angle distribution.

318 To consider the gains that could realistically be achieved by breeding, given the variability

319 we observed, we also computed the \% loss of daily carbon gain using the "fast" acclimating

320 genotypes as the baseline for comparison with "slow" genotypes, rather than using

321 instantaneous acclimation as the baseline (Fig 6b). The relative advantage of faster

322 acclimation was greatest for sunflecks of short to intermediate duration; for example, for 8- 
323 min sunflecks, "slow" genotypes gained 2.9 to $4.3 \%$ less carbon over a day than "fast"

324 genotypes.

325

\section{Discussion}

327 We found greater than two-fold variation across genotypes of wheat in the time required

328 for $95 \%$ photosynthetic induction ( $t_{95}$ ) after exposure to saturating light, both for maximum

329 photosynthesis rate in penultimate leaves and more specifically for carboxylation capacity in

330 flag leaves. Our simulations suggest that diurnal carbon gain is depressed by up to $15 \%$ by

331 non-instantaneous induction of photosynthesis in sunflecks, and is up to $4 \%$ lower in the

332 "slowest" genotypes that we studied as compared to the "fastest". This complements recent

333 work (Taylor \& Long, 2017) documenting the potential impacts on carbon gain of slow

334 Rubisco induction in sunflecks by demonstrating variation in this important trait in available

335 genetic resources, showing that realistic gains are achievable even using traditional

336 breeding.

Variation in induction kinetics

339 Our preliminary analysis of 58 wheat genotypes suggested wide variation in acclimation

340 kinetics, with genotype median $t_{95}$ varying 2.82-fold overall (2.66-fold among the 37

341 genotypes for which we had at least two measurements), and our laboratory study with

342 balanced replication $(n=5)$ within ten genotypes found 1.6-fold variation in genotype

343 median $t_{95}$ for $V_{\text {cmax }}$ induction. Up till now there has been little information about diversity of

344 photosynthetic induction kinetics across wheat genotypes, however Soleh et al. (2017)

345 found wide variation across 37 soybean cultivars and noted that this variation was

346 genetically determined (i.e. stable across different leaf positions and phenological stages).

347 As in our study in wheat, differences among soybean genotypes were attributed largely to

348 variation in the rate of Rubisco activation. Additionally, induction kinetics were not

349 correlated with steady-state photosynthetic capacity, and there was little evidence for this

350 in our study (Fig S4). This observation, if held true over a broader range of studies has large

351 ramifications for breeding approaches based upon the magnitude of $A_{\text {max }}$ in particular those

352 focused solely on the flag leaf. Based on evidence presented here, efforts to improve net

353 carbon capture across canopies must also consider the responses of $A$ to short term changes 
354 in the environment as a dynamic acclimation property that is at least partially genetically

355 determined (Murchie et al. 2018).

356

357 Acclimation of $A_{\max }$ in field-grown penultimate leaves differed markedly from acclimation of

$358 V_{\text {cmax }}$ in chamber-grown flag leaves. The former was sigmoidal with time, having a lag phase

359 and longer $t_{95}$ (median $12.62 \mathrm{~min}$ ), whereas the latter was double-exponential with time,

360 with no lag and shorter $t_{95}$ (median $8.25 \mathrm{~min}$ ). These differences are not necessarily

361 surprising, given the numerous differences between the two experiments; we initially

362 discovered wide variation in $t_{95}$ for $A_{\max }$ in the field experiment, and then designed the $V_{c \max }$

363 experiment to be comparable to that of Taylor and Long (2017) rather than the $A_{\max }$

364 experiment. We note, however, that the 'rise time' $\left(t_{75}-t_{25}\right.$, the time required for $A_{\max }$ or

$365 V_{\text {cmax }}$ to rise through the middle $50 \%$ of its dynamic range) was more similar between the

366 two experiments (median $3.26 \min$ for $A_{\max }$ Vs 2.60 min for $V_{c \max }$ ) than was $t_{95}$, which may

367 suggest that different processes give rise to the lag and rise phases. Future work should test

368 for effects of leaf rank and growth environment under otherwise identical conditions, and

369 should aim to determine whether the lag phase observed in $A_{\max }$ induction occurs when

370 leaves are pre-acclimated in low PPFD rather than darkness, as is more realistic for leaves in

371 a natural canopy.

372

373 Photosynthetic induction has long been known to involve at least two phases. The initial,

374 fast phase to involve availability of RuBP or other Calvin cycle intermediates and is complete

375 within 1-2 minutes (Pearcy 1990), which is consistent with the median $t_{95}$ that we found for

376 the fast phase of $V_{\text {cmax }}$ induction (within-genotype median $\tau_{\text {fast }}=19.1 \mathrm{sec}$, which gives $t_{95}=$

$37757 \mathrm{sec}$ ). The slower phase apparently involves light-dependent activation of Rubisco by

378 Rubisco activase (Rca), with time constants of 4-5 min reported for Alocasia and Spinacia

379 oleracea (Pearcy 1990) (cf. 2.6 - $5.6 \mathrm{~min}$ for $\tau_{\text {slow }}$ in this study). In low light, sugar phosphates

380 bind to Rubisco active sites, inhibiting carboxylation of RuBP. To restore normal function,

381 Rubisco activase (Rca) uses energy from ATP hydrolysis to actively remove these inhibitors.

382 Rca is sensitive to the chloroplast ADP/ATP ratio and redox status and so mediates Rubisco

383 activation in response to light (Carmo-Silva et al. 2015). The variation in Rubisco activation

384 kinetics found among wheat genotypes in our study could possibly be attributed to

385 differences in (1) the total concentration of Rca, (2) the relative concentrations of the $\alpha$ - and 
$386 \quad \beta$-Rca isoforms to each other, (3) the binding affinities of Rubisco to inhibitors and of Rca to

387 Rubisco, and (4) the localization of Rca relative to Rubisco. In rice, Rca overexpressing

388 mutants maintain higher Rubisco activation states in the dark and respond more quickly to

389 changes in the light environment than wild type plants (Yamori et al. 2012). Arabidopsis

390 mutants expressing only the $\beta$-Rca isoform - less sensitive to chloroplast redox status and

391 ADP/ATP ratio than $\alpha$-Rca - had faster photosynthetic induction rates and exhibited

392 increased growth under fluctuating light compared to plants with both isoforms (Carmo-

393 Silva \& Salvucci 2013). As for the binding affinities and co-localization of these two enzymes,

394 much less is known (for a review of current knowledge please see Mueller-Cajar et al. 2014)

395 and future work should seek to address these gaps in knowledge. The recent

396 characterization of the wheat Rca gene structure, as well as advances in genomic, proteomic

397 and transcriptomic techniques, should provide a better understanding of these limitations

398 and allow for a more targeted breeding approach to improve photosynthesis under dynamic

399 light conditions (Carmo-Silva et al. 2015).

400

We did not measure deacclimation kinetics, but for modeling we assumed deacclimation

kinetics in shadeflecks to be slower than acclimation in sunflecks by a factor of $5 / 3$ (1.67),

following Taylor and Long (2017). However, other evidence suggests deacclimation kinetics

may be much slower still (e.g., 22-30 min in Alocasia and Spinacia; Pearcy 1990), which may

mitigate the inferred benefits of breeding for faster acclimation, as discussed below.

Impact of slow induction on photosynthesis

408 Consistent with the recent report by Taylor and Long (2017), our modeling found that noninstantaneous acclimation of photosynthesis to fluctuating light can reduce daily carbon gain by up to $15 \%$. The present study extends that conclusion by quantifying the potential impact of varying sunfleck duration, canopy position (which influences the relative proportions of time spent by leaves in sunflecks vs. shadeflecks) and leaf orientation. Specifically, we found that the impact of slow acclimation was greatest for short sunflecks,

414 because when sunflecks are similar to or much longer than the $t_{95}$ for acclimation, leaves

415 will be fully acclimated for most of each sunfleck, and thus losing little potential carbon gain. 416 Leaf orientation had very small effects (Fig S5). The effect of canopy position was also fairly 
small in most cases (Fig 6), though projected \% carbon losses due to slow acclimation were generally greatest at intermediate canopy depths (cumulative LAI $=0.75 \mathrm{~m}^{2} \mathrm{~m}^{-2}$ ).

An important exception was for leaves of slow-acclimating genotypes in upper canopy layers $\left(\mathrm{LAl}=0.25 \mathrm{~m}^{2} \mathrm{~m}^{-2}\right)$, which our simulations suggested would experience only half as much daily carbon loss as lower-canopy leaves ( $L A=1.5 \mathrm{~m}^{2} \mathrm{~m}^{-2}$ ) (7.6 vs $15.9 \%$ ) for very short sunflecks (< $1 \mathrm{~min})$. In fact, for upper-canopy leaves with very short sunflecks, slowacclimating genotypes actually had a slight advantage over fast genotypes in our simulations (dashed black line in Fig 6b). This is a consequence of the wider range that we observed (and which we used to drive the simulations) for $\tau_{\text {fast }}$ (upper and lower deciles $=0.54$ and $0.05 \mathrm{~min}$, respectively) vs $\tau_{\text {slow }}(5.6 \mathrm{vs} 2.6 \mathrm{~min}$ ). This meant that the faster and thus greater downregulation in "fast" genotypes during short shadeflecks left them at a lower initial photosynthetic rate at the start of the subsequent sunfleck than "slow" genotypes, which outweighed the benefits of their faster upregulation during sunflecks (Fig 7a). For longer shadeflecks, the reverse was true (Fig 7b). However, we emphasize that this result depends heavily on the assumed kinetics of photosynthetic deacclimation during shadeflecks; as noted earlier, we assumed, following Taylor and Long (2017), that the time constants for deacclimation were 1.67 times greater than for acclimation. Had we instead assumed deacclimation to be 4-6 times slower than acclimation, as suggested by some data (Seeman et al 1988; Woodrow \& Mott 1989; Way \& Pearcy 2012), it is unlikely that 'slow' acclimating genotypes would have a carbon gain advantage except perhaps in extremely brief sunflecks. This highlights the need for future work to quantify the kinetics of deacclimation.

In very short sunflecks, other factors may dominate dynamics of photosynthesis. For example, buffering of high-frequency $(10-0.1 \mathrm{~Hz})$ fluctuations in light availability by the 'capacitance' afforded by finite metabolite pools can increase the effective light use efficiency of very high sunfleck PPFDs above $100 \%$, as compared to the average photosynthesis rate when the same PPFD is sustained (Pearcy 1990). Rubisco acclimation and deacclimation are probably not relevant to such short sunflecks, which may dominate canopy light regimes under windy conditions, or for plants with very small leaves. 
448 By driving our simulations with observed variation in acclimation kinetics within existing

449 genetic resources for wheat, we were also able to quantify the realistic gains in diurnal

450 carbon capture that should be possible with traditional breeding. We found that the slowest

451 genotypes (modeled using the the highest decile for $\tau_{\text {slow }}$ ) gained up to $4 \%$ less carbon, daily,

452 than the fastest (modeled using the lowest decile for $\tau_{\text {slow }}$ ), and that the potential gains

453 were greatest for leaves at intermediate canopy positions (LAI $=0.75$ and $1.5 \mathrm{~m}^{2} \mathrm{~m}^{-2}$ ) and

454 for sunflecks of short to intermediate duration (2-16 min) (Fig 6b). Although these potential

455 gains are not as dramatic as the "headline" numbers of $15-20 \%$ based on instantaneous

456 acclimation as the target, they are nevertheless worth pursuing and are sufficiently

457 conservative within genotypes to be a feasible target for breeders. We suggest that

458 continuing work should therefore aim to further quantify variation in this important trait

459 across genotypes of wheat, and to identify target genomic regions to assist breeding efforts.

460 In this capacity, we note that our test of the "single-point" $A$ vs $c_{\mathrm{i}}$ method produced very

461 reliable inference of $V_{c \max }$ during induction (Fig S6), suggesting that induction kinetics can be

462 reliably quantified with as little as one-tenth the time investment per leaf as required for

463 the full dynamic $A$ vs $c_{i}$ method used in this study.

\section{Conclusions}

466 Our study has for the first time identified significant variation in the acclimation time of photosynthesis following dark-to-light transitions across a diverse panel of wheat genotypes, under field and controlled conditions. Slow acclimation of photosynthesis reduced daily carbon assimilation by as much as $16 \%$. These results reinforce the findings of Taylor \& Long (2017) in highlighting fast acclimation of photosynthesis, in particular the activation of Rubisco, to fluctuating light as a valuable trait for improvement in wheat

472 breeding programs. 


\section{Supporting Information}

476 File S1:

477 - Appendix S1. Modeling impact of acclimation kinetics on carbon gain.

478 - Table S1. List of genotypes.

479 - Figure S1. Phenological stages at time of measurements.

480 - Figure S2. Validation of $A_{\max }$ in TPU-limited conditions.

481 - Figure S3. Intercellular $\left[\mathrm{CO}_{2}\right]$ at RuBP carboxylation/regeneration transition during

482 induction.

483 - Figure S4. Relationship between final $A_{\max }$ and $V_{\text {cmax }}$ rates and $t_{95}$ and $t_{75}-t_{25}$.

484 - Figure S5. Effect of leaf orientation on diurnal carbon losses due to slow induction.

485 - Figure S6. Comparison of default and "one-point" $A$ vs. $c_{i}$ fitting methods.

487 File S2:

488 - R script for dynamic A vs ci curve fitting

$489-$ R script for analysis of acclimation kinetics

490

491 File S3:

492 - CSV file containing extracted kinetics parameters.

\section{Acknowledgements}

495 This research was supported by the International Wheat Yield Partnership, through a grant

496 provided by the Grains Research and Development Corporation (US00082). TNB was

497 supported by the Australian Research Council (DP150103863 and LP130100183) and the

498 National Science Foundation (Award \#1557906). This work was supported by the USDA

499 National Institute of Food and Agriculture, Hatch project 1016439. 


\section{References}

Bernacchi CJ, Singsaas EL, Pimentel C, Portis ARJ, Long SP. 2001. Improved temperature response functions for models of Rubisco-limited photosynthesis. Plant, Cell and Environment 24, 253-259. Busch FA, Sage RF, Farquhar GD. 2018. Plants increase $\mathrm{CO}_{2}$ uptake by assimilating nitrogen via the photorespiratory pathway. Nature Plants 4, 46-54.

Carmo-Silva AE, Salvucci ME. 2013. The regulatory properties of Rubisco activase differ among species and affect photosynthetic induction during light transitions. Plant Physiology 161, 16451655.

Carmo-Silva E, Scales JC, Madgwick PJ, Parry MAJ. 2015. Optimizing Rubisco and its regulation for greater resource use efficiency. Plant Cell and Environment 38, 1817-1832.

De Kauwe MG, Lin YS, Wright IJ, Medlyn BE, Crous KY, Ellsworth DS, Maire V, Prentice IC, Atkin OK, Rogers A, Niinemets U, Serbin SP, Meir P, Uddling J, Togashi HF, Tarvainen L, Weerasinghe LK, Evans BJ, Ishida FY, Domingues TF. 2016. A test of the 'one-point method' for estimating maximum carboxylation capacity from field-measured, light-saturated photosynthesis. New Phytologist 210, 1130-1144.

de Pury DGG, Farquhar GD. 1997. Simple scaling of photosynthesis from leaves to canopies without the errors of big-leaf models. Plant, Cell and Environment 20, 537-557.

Duursma RA. 2015. Plantecophys - An R package for analysing and modelling leaf gas exchange data. Plos One 10, 13.

Farquhar GD, Caemmerer SV, Berry JA. 1980. A biochemical-model of photosynthetic $\mathrm{CO}_{2}$ assimilation in leaves of C-3 species. Planta 149, 78-90.

Kromdijk J, Głowacka K, Leonelli L, Gabilly ST, Iwai M, Niyogi KK, Long SP. 2016. Improving photosynthesis and crop productivity by accelerating recovery from photoprotection. Science $\mathbf{3 5 4}$, 857-861.

Lawson T, Vialet-Chabrand S. 2018. Speedy stomata, photosynthesis and plant water use efficiency. New Phytologist.

Long SP, Zhu XG, Naidu SL, Ort DR. 2006. Can improvement in photosynthesis increase crop yields? Plant Cell and Environment 29, 315-330.

Morales A, Kaiser E, Yin X, Harbinson J, Molenaar J, Driever SM, Struik PC. 2018. Dynamic modelling of limitations on improving leaf $\mathrm{CO}_{2}$ assimilation under fluctuating irradiance. Plant, cell \& environment 41, 589-604. 
Mueller-Cajar O, Stotz M, Bracher A. 2014. Maintaining photosynthetic $\mathrm{CO}_{2}$ fixation via protein remodelling: the Rubisco activases. Photosynthesis Research 119, 191-201.

Murchie EH, Kefauver S, Ortega JLA, Muller O, Rascher U, Flood PJ, Lawson T. 2018.

Photosynthesis: a fast-changing process in an even faster world (Invited Review). Annals of botany $122,207-220$.

Pearcy RW. 1990. Sunflecks and photosynthesis in plant canopies. Annual Review of Plant Physiology and Plant Molecular Biology 41, 421-453.

Portis AR, Salvucci ME, Ogren WL. 1986. Activation of ribulosebisphosphate carboxylase/oxygenase at physiological $\mathrm{CO} 2$ and ribulosebisphosphate concentrations by Rubisco activase. Plant Physiology 82, 967-971.

Retkute R, Townsend AJ, Murchie EH, Jensen OE, Preston SP. 2018. Three-dimensional plant architecture and sunlit-shaded patterns: a stochastic model of light dynamics in canopies. Annals of botany.

Salter WT, Gilbert ME, Buckley TN. 2018. A multiplexed gas exchange system for increased throughput of photosynthetic capacity measurements. Plant Methods $14,80$.

Seemann JR, Kirschbaum MUF, Sharkey TD, Pearcy RW. 1988. Regulation of ribulose-1,5bisphosphate carboxylase activity in Alocasia-macrorrhiza in response to step changes in irradiance. Plant Physiology 88, 148-152.

Slattery RA, Walker BJ, Weber AP, Ort DR. 2018. The impacts of fluctuating light on crop performance. Plant Physiology 176, 990-1003.

Soleh MA, Tanaka Y, Kim SY, Huber SC, Sakoda K, Shiraiwa T. 2017. Identification of large variation in the photosynthetic induction response among 37 soybean Glycine max (L.) Merr. genotypes that is not correlated with steady-state photosynthetic capacity. Photosynthesis Research 131, 305-315.

Soleh MA, Tanaka Y, Nomoto Y, Iwahashi Y, Nakashima K, Fukuda Y, Long SP, Shiraiwa T. 2016. Factors underlying genotypic differences in the induction of photosynthesis in soybean Glycine max (L.) Merr. Plant Cell and Environment 39, 685-693.

Taylor SH, Long SP. 2017. Slow induction of photosynthesis on shade to sun transitions in wheat may cost at least $21 \%$ of productivity. Philosophical Transactions of the Royal Society B-Biological Sciences 372, 9.

Way DA, Pearcy RW. 2012. Sunflecks in trees and forests: from photosynthetic physiology to global change biology. Tree Physiology 32, 1066-1081. 
Woodrow IE, Mott KA. 1989. Rate limitation of non-steady-state photosynthesis by ribulose-1,5bisphosphate carboxylase in spinach. Australian Journal of Plant Physiology 16, 487-500.

Yamori W, Masumoto C, Fukayama H, Makino A. 2012. Rubisco activase is a key regulator of nonsteady-state photosynthesis at any leaf temperature and, to a lesser extent, of steady-state photosynthesis at high temperature. Plant Journal 71, 871-880. 


\section{Figure legends}

Figure 1. Representative time-courses of simulated PPFD with alternating sunflecks and shadeflecks (solid lines, left axis) and the fraction of time spent in sunflecks by leaves (dashed lines, right axis), for two canopy positions: cumulative leaf area indices of (a) 0.25 $\mathrm{m}^{2} \mathrm{~m}^{-2}$, and (b) $1.5 \mathrm{~m}^{2} \mathrm{~m}^{-2}$. Simulations assumed a constant sunfleck duration of 16 minutes.

Figure 2. Two examples of dynamic $A$ vs $c_{i}$ curves, for a leaf with relatively slow acclimation of photosynthesis to light (a; time for $V_{\text {cmax }}$ to increase by $95 \%$ of the difference from its initial value to its final value, $t_{95}=12.5 \mathrm{~min}$ ), and a leaf with faster acclimation ( $b ; t_{95}=5.8$ min). In each panel, each curve comprises a Rubisco carboxylation-limited segment (solid lines) and an RuBP regeneration-limited segment (dashed lines), and four curves are shown, each corresponding to a different time after exposure to saturating PPFD (yellow: $1 \mathrm{~min}$; orange: $2.5 \mathrm{~min}$; green: $7.5 \mathrm{~min}$; blue: $15 \mathrm{~min}$ ).

Figure 3. Representative time-courses of $\mathrm{CO}_{2}$ - and light-saturated net assimilation rate measured in field-grown plants $\left(A_{\max } ;\right.$ a) and carboxylation capacity inferred from dynamic $A$ vs $c_{i}$ curves measured on chamber-grown plants $\left(V_{\text {cmax }} ; b\right)$. The time at which $A_{\max }$ or $V_{c \operatorname{cmax}}$ rose through $95 \%$ of its dynamic range $\left(t_{95}\right)$ is shown with a vertical grey bar in both panels. Solid black lines indicate model fits (a: Eqn 3; b: Eqn 2); in (b), the dashed and dash-dot lines represent the fast and slow phases of the model for $V_{c \max }$ induction, respectively (each adjusted to the same asymptote as the full model).

Figure 4. Distribution of values of $(a, c) t_{95}$ and $(b, d) t_{75}-t_{25}$, the time for Amax $(a, b)$ or Vcmax (c,d) to increase through $95 \%$ of its dynamic range (t95), or through the middle $50 \%$ of its dynamic range (t75 - t25). 58 genotypes were studied for (a) and (b), of which 37 had 2-4 replicates; 10 genotypes were studied for $(c)$ and (d), each with 5 replicates. The center line in each box plot indicates the median, the upper and lower bounds of each box indicate the 75th and 25th percentiles, respectively, the whiskers indicate the 90th and 10th percentiles, respectively, and the black circles indicate individual values above or below the latter percentiles. Distributions for all genotypes combined are shown at right. 
Figure 5. Time-courses for acclimation of normalized $V_{\text {cmax }}$ for leaves using the lower decile (orange line) and upper decile (blue dashed line) for the time constants, $\tau_{\text {slow }}$ and $\tau_{\text {fast }}$ of the slow and fast phases of $V_{\text {cmax }}$ acclimation. Blue line: $\tau_{\text {slow }}=5.4 \mathrm{~min}, \tau_{\text {fast }}=0.54 \mathrm{~min}$; orange line: $\tau_{\text {slow }}=2.6 \mathrm{~min}, \tau_{\text {fast }}=0.05 \mathrm{~min}$.

Figure 6. Simulated percent loss of potential total diurnal carbon gain caused by slow acclimation of photosynthesis to fluctuating light. In (a), the baseline for comparison is instantaneous acclimation, and the solid and dashed lines are results using the 10th and 90th percentiles, respectively, of kinetic parameters $\left(\tau_{\text {slow }}\right.$ and $\tau_{\text {fast }}$, the time constants for the slow and fast phases of acclimation of $V_{\text {cmax }}$ ) to model acclimation. In (b), the baseline for comparison is the faster-acclimating genotypes represented by solid lines in (a). Black, red, blue and grey lines are simulations at four different canopy depths $(0.25,0.75,1.5$ and $3.0 \mathrm{~m}^{2} \mathrm{~m}^{-2}$ cumulative leaf area index, respectively). All results are averaged across a spherical leaf angle distribution using Monte Carlo sampling, as described in the main text.

Figure 7. Simulated dynamics of net assimilation rate during sunflecks, and the acclimated target value of assimilation rate during shadeflecks, showing that fast-acclimating leaves (red symbols) are actually at a disadvantage relative to slow-acclimating leaves (blue symbols) when sunflecks are long and shadeflecks are short, as in panel (a). Simulations are show for horizontal leaves at mid-day at two canopy positions: cumulative leaf area indices of (a) $0.25 \mathrm{~m}^{2} \mathrm{~m}^{-2}$, and (b) $1.5 \mathrm{~m}^{2} \mathrm{~m}^{-2}$. Black symbols are for instantaneous acclimation; red and blue symbols are for "fast" and "slow" acclimation, respectively, which were modeled using the 10th and 90th percentiles, respectively, of parameters for acclimation kinetics ( $\tau_{\text {slow }}$ and $\tau_{\text {fast }}$, the time constants for the slow and fast phases, respectively, of acclimation of $\left.V_{\text {cmax }}\right)$. Sunfleck length was the same in all cases $(2.0 \mathrm{~min})$, whereas shadefleck length was greater at the lower canopy position to reflect the greater fraction of time spent in shadeflecks by lower-canopy leaves. 
Figures

Figure 1

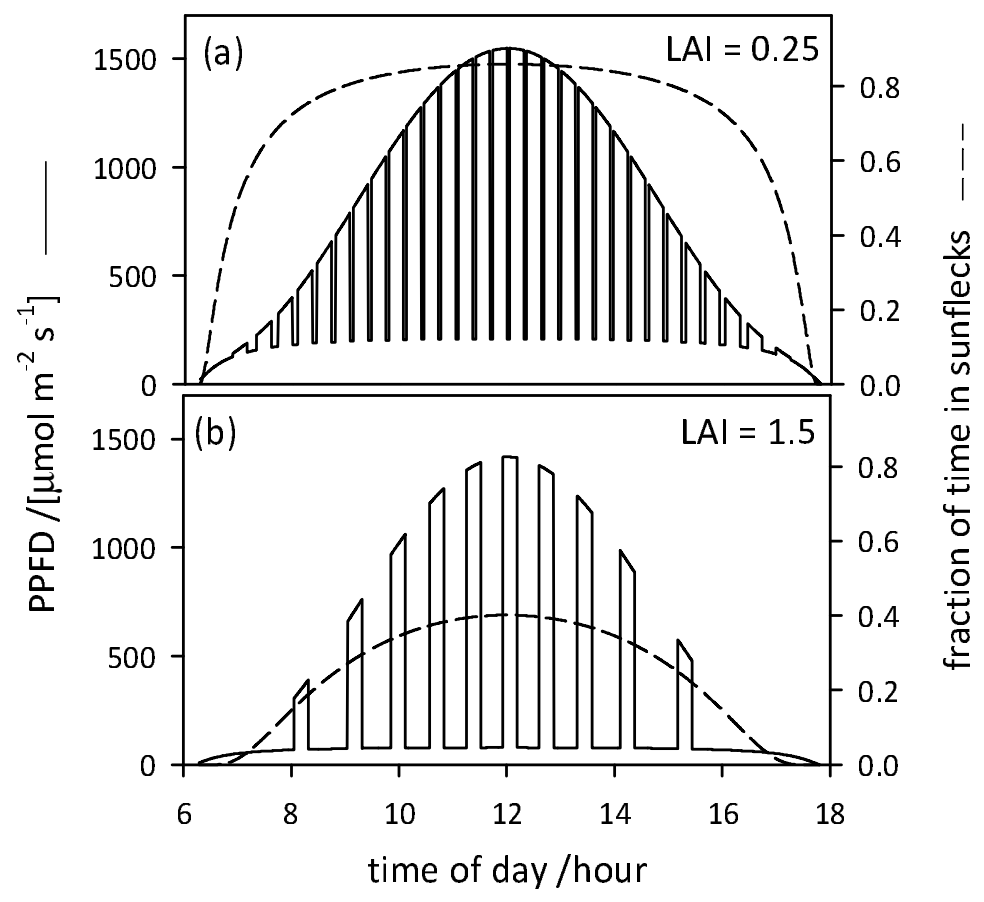


bioRxiv preprint doi: https://doi.org/10.1101/435834; this version posted October 5, 2018. The copyright holder for this preprint (which was not certified by peer review) is the author/funder, who has granted bioRxiv a license to display the preprint in perpetuity. It is made available under aCC-BY 4.0 International license.

\section{Figure 2}
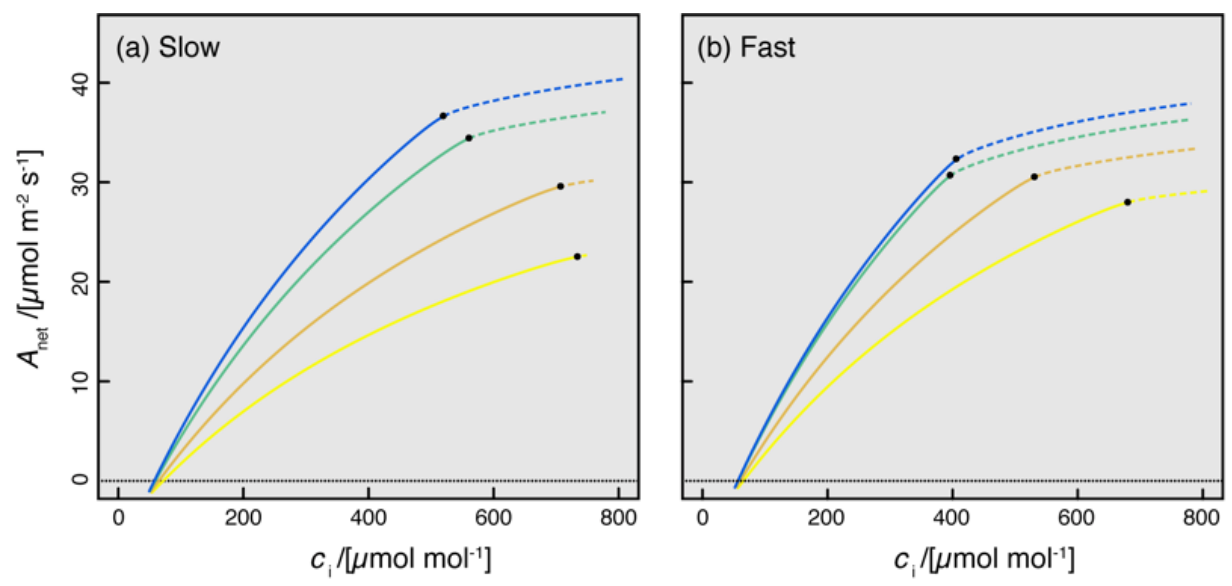

Time after induction

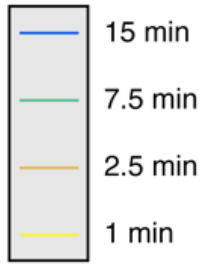




\section{Figure 3}
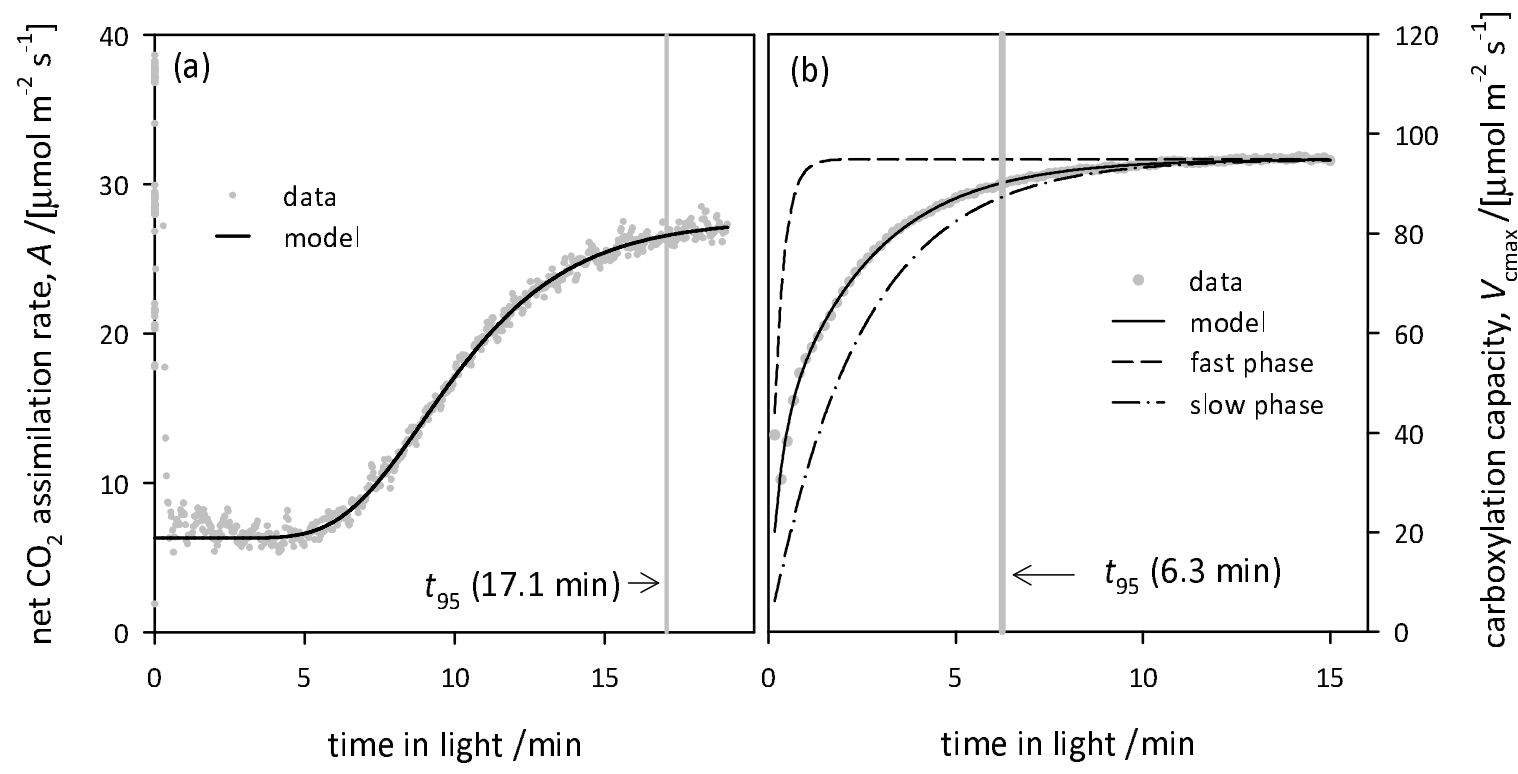
bioRxiv preprint doi: https://doi org/10 1101/435834; this version posted October 5, 2018. The copyright holder for this preprint (which was not certified by peer review) is the author/funder, who has granted bioRxiv a license to display the preprint in perpetuity. It is made available under aCC-BY 4.0 International license.

\section{Figure 4}

\section{a}

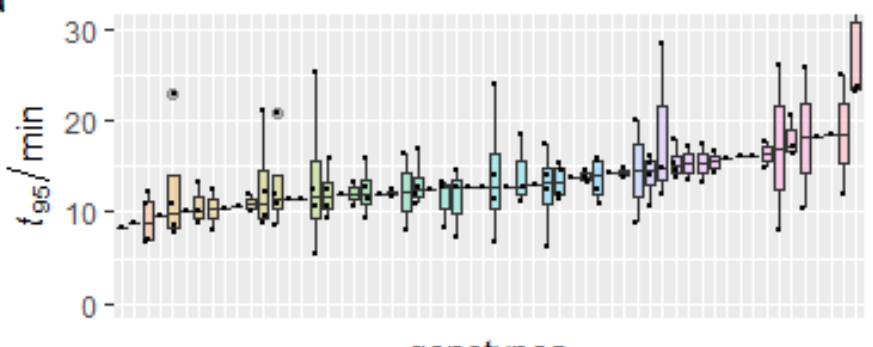

genotypes

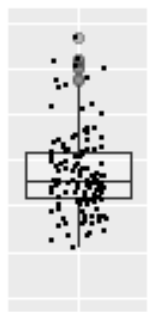

all gt

b
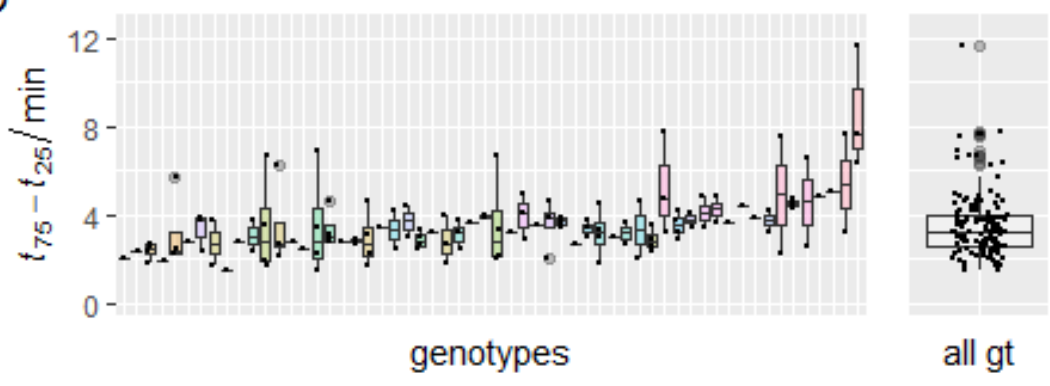

C

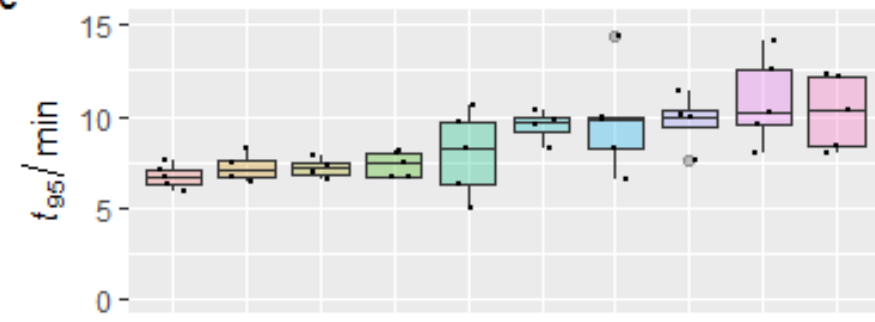

genotypes

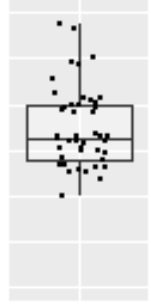

all gt

d

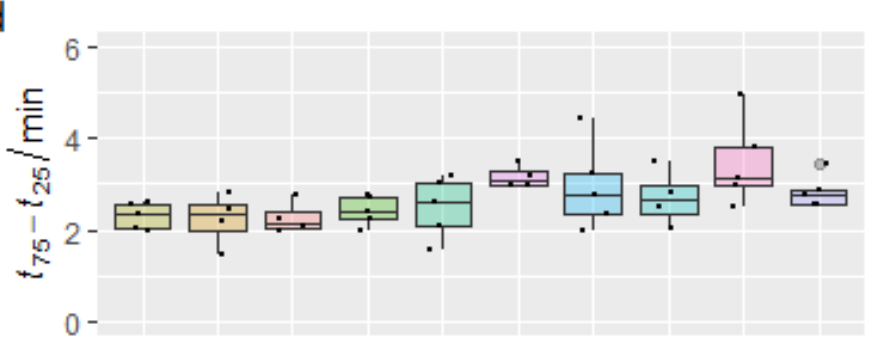

genotypes

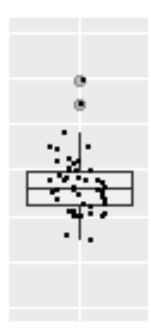

all gt 
bioRxiv preprint doi: https://doi.org/10.1101/435834; this version posted October 5, 2018. The copyright holder for this preprint (which was not certified by peer review) is the author/funder, who has granted bioRxiv a license to display the preprint in perpetuity. It is made available under aCC-BY 4.0 International license.

\section{Figure 5}

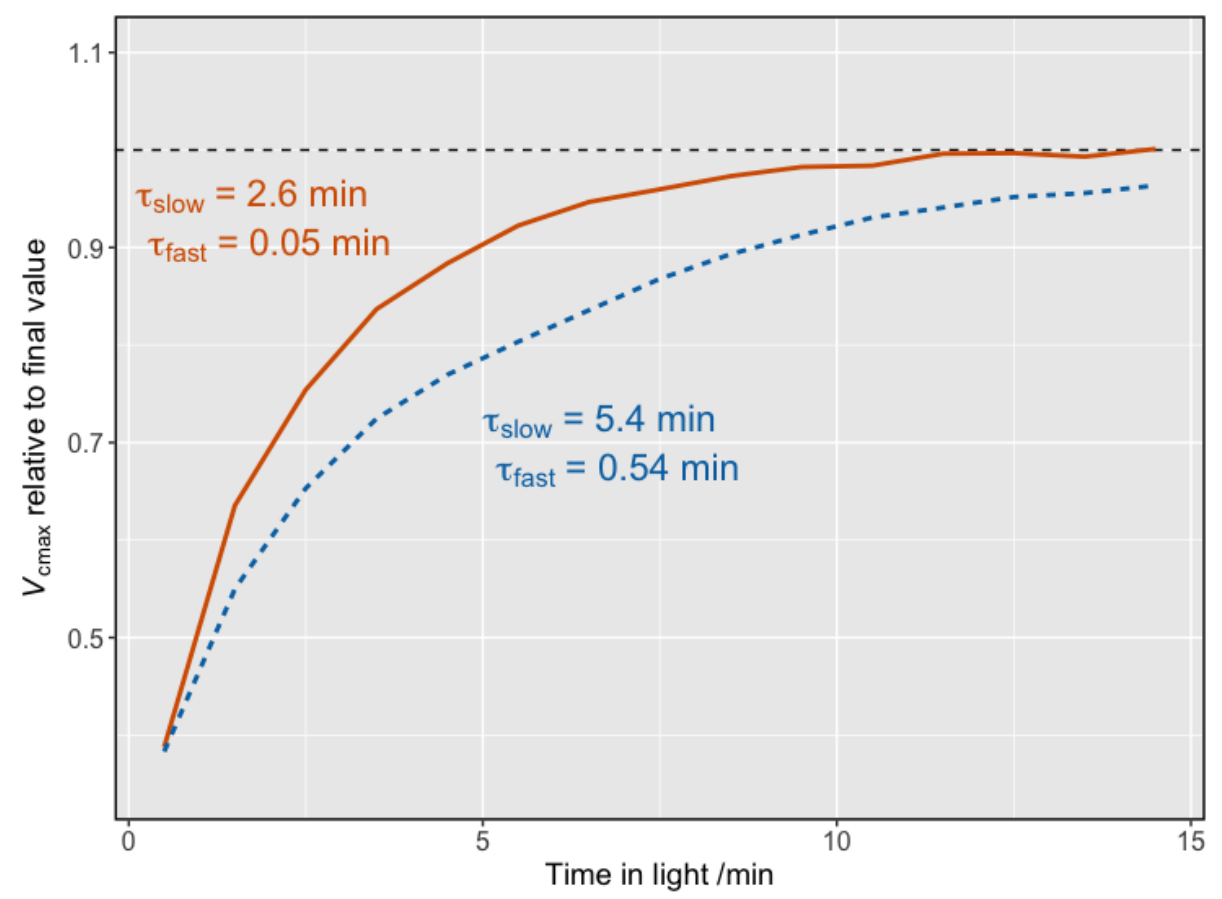


bioRxiv preprint doi: https://doi.org/10.1101/435834; this version posted October 5, 2018. The copyright holder for this preprint (which was not certified by peer review) is the author/funder, who has granted bioRxiv a license to display the preprint in perpetuity. It is made available under aCC-BY 4.0 International license.

\section{Figure 6}

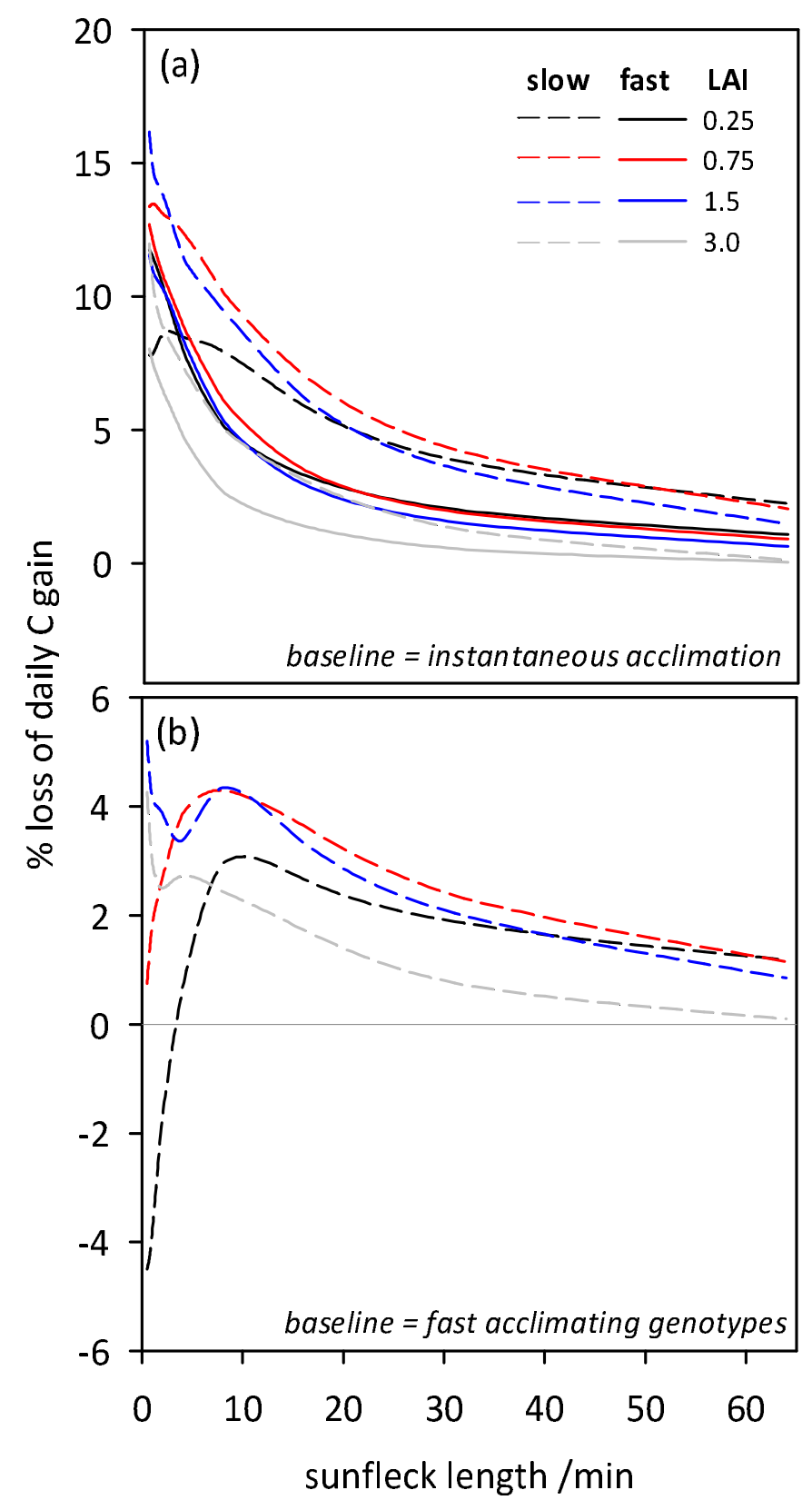


bioRxiv preprint doi: https://doi.org/10.1101/435834; this version posted October 5, 2018. The copyright holder for this preprint (which was not certified by peer review) is the author/funder, who has granted bioRxiv a license to display the preprint in perpetuity. It is made available under aCC-BY 4.0 International license.

\section{Figure 7}

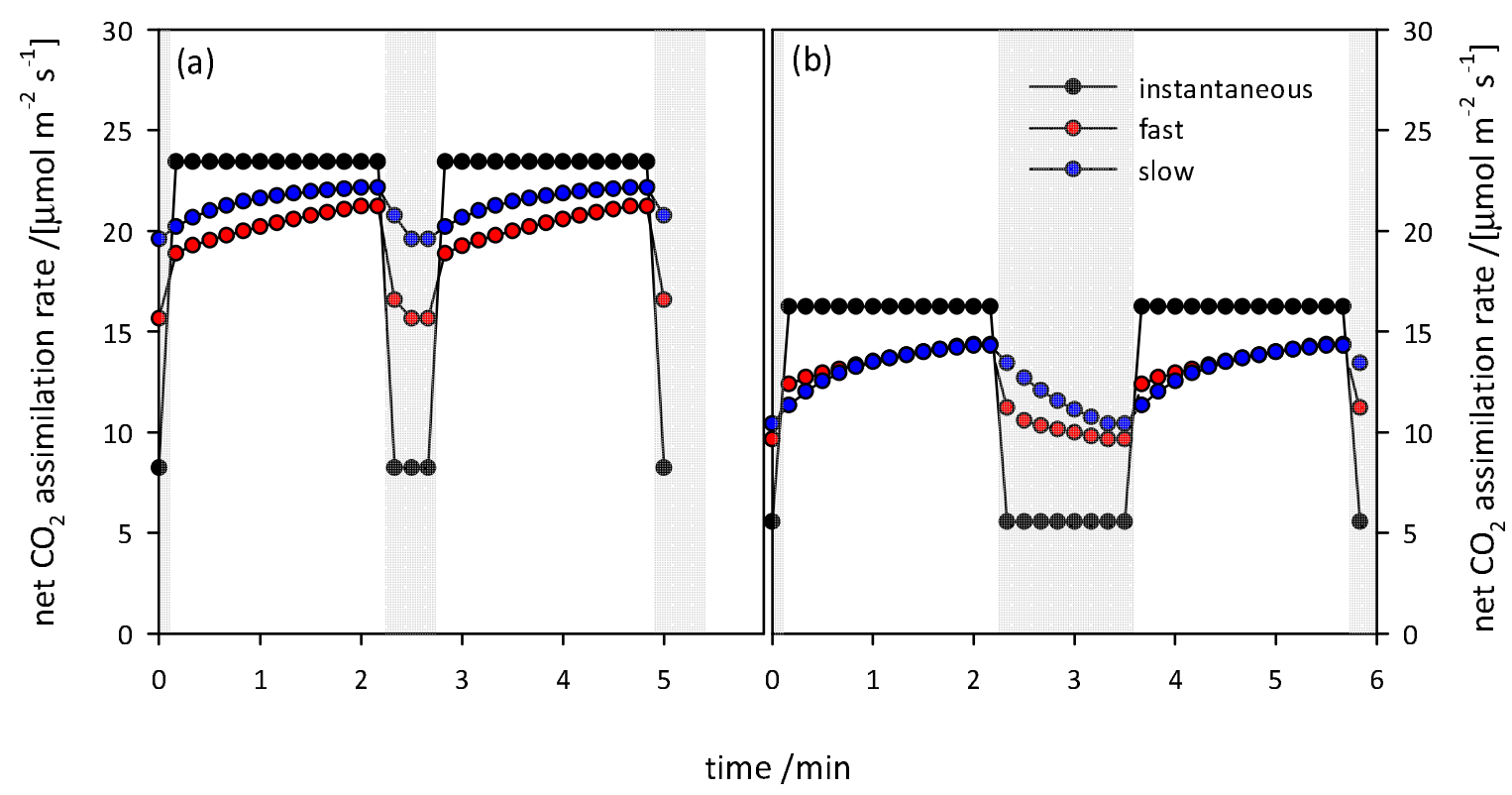

